\title{
Wine and music (I): on the crossmodal matching of wine and music
}

\author{
Charles Spence ${ }^{*}$ and Qian (Janice) Wang
}

\begin{abstract}
For years now, wine writers have been tempted to describe certain wines in terms of musical metaphors and analogies. Until recently, however, it has never been altogether clear how widely shared, and hence meaningful, such surprising cross-sensory connections really were. A growing body of scientific evidence, however, now shows that regular consumers (i.e. non-experts) do reliably match certain wines with particular pieces of music (under conditions of forced choice). When questioned, people also feel that certain wines go well with specific pieces of music, while others do not. As such, it can be argued that describing wines in musical terms can potentially provide useful information concerning the likely sensory, descriptive, analytic and/or hedonic properties of the wine. While some commentators have sought for an explanation for such crossmodal matches in terms of synaesthesia, here we argue that crossmodal correspondences - the associations that the majority of us share between tastes, aromas, flavours, and mouthfeel characteristics on the one hand and particular properties of sound and music on the other-offer a more satisfactory explanation for what may be going on. In particular, we highlight how structural, statistical, semantic and affective correspondences could all play a part in explaining the affinity that so many of us feel between wine and music.
\end{abstract}

Keywords: Wine, Music, Crossmodal correspondences, Multisensory, Synaesthesia, Emotion, Crossmodal matching

\section{Review}

\section{Describing wine musically}

Read the wine press and before too long you will likely stumble across a writer trying to describe a wine by drawing a link with a specific musician, or piece, or type, of music (see [1], for a review). Just take the following as representative: "I have tasted first-attempt Chardonnays that were like Dizzy Gillespie's solos: all over the place. And the colour of his trumpet, too. On the other hand a Stony Hill Chardonnay recently had the subtle harmonies and lilting vitality of Bix Beiderbecke. Robert Mondavi's Reserve Cabernets are Duke Ellington numbers: massed talent in full cry. Benny Goodman is a Riesling from Joseph Phelps, Louis Martini's wines have the charm and good manners of Glenn Miller. Joe Heitz, though, is surely Armstrong at the Sunset Café; virtuoso, perverse and glorious." ([2] p. 253).

The drawing of such links between music and wine is by no means unusual; ${ }^{1}$ the question that we wish to

\footnotetext{
* Correspondence: charles.spence@psy.ox.ac.uk

Crossmodal Research Laboratory, Department of Experimental Psychology, University of Oxford, Oxford OX1 3UD, UK
}

address in this review is why. Why, exactly, do people find it so natural to draw an analogy between these two distinctive and un-confusable kinds of perceptual experience? Why not describe a wine in terms of a painting or painter instead, one might ask? ${ }^{2}$ We are, after all, supposed to be visually dominant creatures, are we not? One of the key questions to be addressed in this article is whether such auditory analogies actually convey any useful information to the reader? Many commentators have been drawn to an explanation for what may be going on here in terms of synaesthesia, ${ }^{3}$ or "oenesthesia" (i.e. oenology + synaesthesia), as Jo Burzynska, a professional wine critic and sound artist from Christchurch, New Zealand, describes the widespread tendency for people to match sounds, instruments, and music to the tastes, aromas, and flavours of wine (see http://stanierblackfive.com/oenosthesia-sound-and-wine/; see also [3]). However, it is our belief that the notion of crossmodal correspondences-the shared associations between distinct attributes, features, and dimensions in different sensory modalities - may provide a firmer base on which to understand the surprising associations we all seem to 
share between music and wine $[4,5]$. Indeed, according to the latest research, people consistently match certain wines with specific pieces of music under conditions of forced choice. They also rate certain pieces of music as matching a wine much better than others. Furthermore, playing certain pieces of music can, in turn, change people's ratings, and hence presumably their experiences, of the wine that they happen to be tasting (see [6] for a review).

However, it is important to note at the outset that not everyone agrees on the similarity between taste and music. The philosophers, in particular, seem to have a problem with this notion. Just take the following from Monroe Beardsley ([7], p. 99) who stated that there are no "taste-symphonies and smell-sonatas". Tefler ([8], p. 20) though qualifies this suggestion, stating that "symphonies and sonatas are exceedingly complex works of art. He should have asked whether there can be tasteand-smell preludes, and the answer is by no means so obvious." Perhaps here one needs to draw a distinction between a perceptual similarity, or correspondence, and some, more formal, structural similarity. In this piece, we will focus on the former.

\section{Crossmodal correspondences between music and wine}

Over the years, a number of distinguished wine writers have been tempted to make a connection between the wine that they are tasting (but which, presumably the reader might not be able to) and a particular piece or style of music (that one presumes is expected to be already familiar, and hence meaningful, to the reader). ${ }^{4}$ Now, here of course, one needs to be careful that one's attempts to match the music to the wine does not simply end up sounding clichéd, as was apparently the case when one of Britain's best loved actor's Simon Callow hosted a series on Classic FM called Tasting Notes. The show was billed as a "musical journey around the winegrowing regions of the world". Journalist Alice Jones was less than impressed with Callow's description of some Mozart and its matching Veneto wine: "A refreshing, luxurious favourite with a zesty grapefruit finish - the perfect partner for Mozart's refulgent, crystal-clear piano concerto in D minor." [9]. Another legitimate concern here is that this connection between sound and taste might turn out to be highly idiosyncratic (as are many of the taste concurrents experienced by auditory-gustatory synaesthetes) and hence may fail to communicate any useful information about the qualities of the wine to whoever might be reading the author's possibly purple prose [1].

The notion that unrelated sensations in different sensory modalities cannot be compared was eloquently and forcefully captured by the early German psychophysicist Hermann Ludwig Ferdinand von Helmholtz who stated way back in 1878 that "the distinctions among sensations which belong to different modalities, such as the differences among blue, warm, sweet, \& high-pitched, are so fundamental as to exclude any possible transition from one modality to another \& any relationship of greater or less similarity. For example, one cannot ask whether sweet is more like red or more like blue... Comparisons are possible only within each modality" [10]. Now, without wishing to disrespect one of the founding fathers of the fields of both experimental psychology and psychophysics, one way in which to ascertain whether certain wines and specific pieces of music do, in fact, share a certain affinity with one another is to have people try to match each of a pre-selected set of wines with one of a small selection of musical excerpts (in what is known as a crossmodal matching task). ${ }^{5}$ The results of a number of such studies certainly give pause to question Helmholtz's strident assertion.

\section{Wine-music matching}

At its simplest, take a white and a red wine (let us say a Sauvignon Blanc and a Malbec) and two pieces of music. We frequently choose something like "Carmina Burana" by Carl Orff or "Nessun Dorma" from the third act of Puccini's Turandot on the one hand and "Poules et Coqs" from Camille Saint-Saën's Carnival of the Animals or track 6/7 from Mike Oldfield's (1973) Tubular Bells on the other. Oftentimes, this kind of demonstration is incorporated into our presentations at science, music and/or gastronomy festivals. Once everyone has two glasses of wine in hand, we play excerpts from the two pieces of music. The audience are encouraged to raise the glass of wine that they feel best matches the music. Assuming that the wines have been picked appropriately, around $75-90 \%$ of people will normally be in agreement, raising their white wine to the Saint-Saën (or Mike Oldfield) and their red wine whenever Carmina Burana (or Nessun Dorma) is blaring out. Such simple demonstrations allow people to see that there is something common (or shared across seemingly incongruent sensory experiences). What they also illustrate is how similar we all feel about what the "right" match is. That said, explaining where, precisely, that feeling of rightness comes from, and what it consists of, is a little harder to do (as we will see later).

In one such event [11], 64 members of the audience (who returned completed score sheets) at a wine tasting event held in Oxford were serenaded with two pieces of live classical music (performed by a duo of musicians from the Royal Academy of Music, London) while tasting a Marcel Martin Sauvignon Blanc 2013, from the Loire Valley in France, and a Para Dos Malbec 2013, from Mendoza, Argentina. ${ }^{6}$ The first piece of music was Debussy's Jardin Sous la Pluie, a virtuosic piano solo 
with many fast passages in a high-pitch range. This piece was chosen to match the white wine, since high tempo and pitch have been shown to be associated with a sour taste and citrus flavours $[12,13]$. The second piece was Rachmaninoff's Vocalise, a piano and cello duet played in a slow tempo. This piece was chosen to match the red wine, since legato articulation and a consonant melody have both been shown in prior research to be matched with sweet tastes and full body $[12,13]$. As expected, the music that had been chosen to be congruent with each of the wines was indeed rated as a better match than the other piece of music. In particular, the Debussy was rated as a significantly better match for the white wine than the Rachmaninoff $(M=53.5$ vs. 40.6 on a 100-point matching scale, $t(61)=2.18, p=.03$ ), while the Rachmaninoff was rated as a significantly better match for the red wine than was the Debussy $(M=65.9$ vs. 49.5 , respectively, $t(48.7)=-2.93, p=.005)$.

At the next stage up, in terms of complexity, are those tasting events in which people are served three or four distinctive wines and are asked to rate how well each one matches a series of carefully selected musical excerpts. Normally, the audience will taste a sparkling wine, a white wine, a red wine and a dessert wine (see $[14,15]$, for representative examples of this type). In the summer of 2013, for instance, a tasting of four wines (two white and two red) was conducted at the premises of The Antique Wine Company in central London.
Twenty-four naive consumers were invited to rate how well they thought that each of the wines matched each one of eight short pre-recorded classical music selections [14]. The results (see Fig. 1) revealed that people felt there to be a natural affinity between the white wine (a 2010 Pouilly-Fumé Silex, Domaine Didier Dagueneau) and Mozart's Flute Quartet in D Movement 1 Allegro. By contrast, a 2004 Château Margaux was matched with excerpts from the second and third movements of Tchaikovsky's String Quartet No 1. Interestingly, there was not such a clear response when it came to matching the Sauternes dessert wine (a 2004 Château Climens) to music; the best match here being with Debussy's Syrinx for Solo Flute. ${ }^{7}$

Meanwhile, at the 2014 Sensibus Festival held in Seinäjoki in Finland [15], 46 individuals were given four distinctive wines to taste-a Taittinger Brut Réserve champagne; a Fernway Sauvignon Blanc 2012 (white); a Chateau Carsin Cuvée Noire 2010 (red); and a Chateau Carsin Liquoreux 2007 (dessert wine). Early on the day of the event, a trio of Finnish rock guitarists had come up with their own musical improvisations on tasting each of the wines (see [15], for a description). The guitarists played the four short improvisations (in a random order) while the members of the audience had to try and guess which wine the musicians had been inspired by after listening to each piece. The results showed that 38 of the 46 audience members chose the same

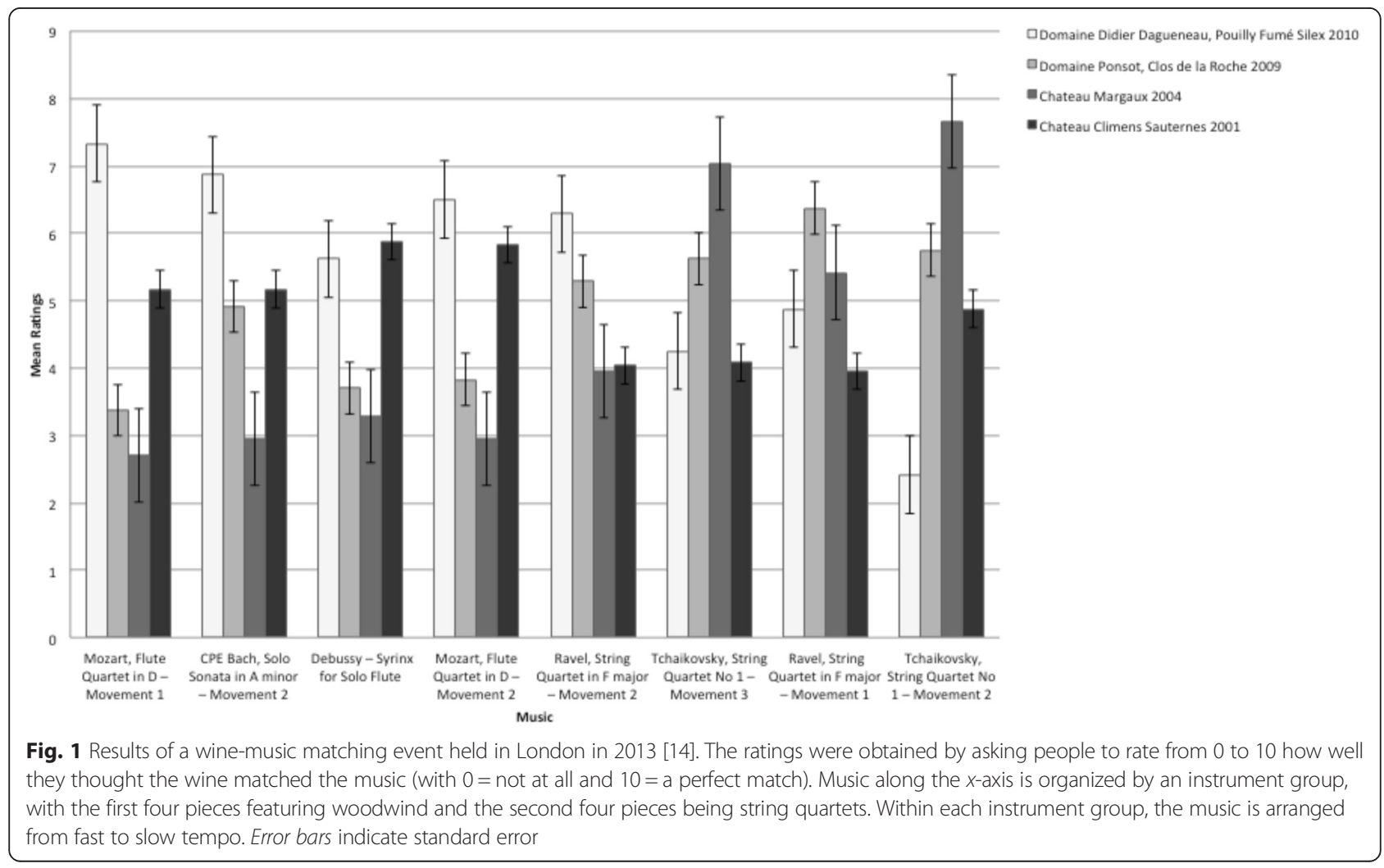


improvisation (actually composed for the Sauvignon Blanc) as matching the Chateau Carsin Cuvée Noire 2010. Thirty-one chose the (Taittinger Brut Réserve) improvisation for the Sauvignon Blanc. Intriguingly, the other two improvisations (for the two Chateau Carsin wines) were paired by nearly 20 people with the champagne and by another 20 or so with the dessert wine. Thus, although the musicians in this case were not all that successful in terms of improvising music to match the specific wines that they had in mind (note that they had not read any of the literature on crossmodal correspondences between music and taste before undertaking this task), the results nevertheless clearly show that the musicians' musical improvisations were associated with a particular wine, or pair of wines, in the minds of those listening to them.

\section{Are people matching the music to the taste/flavour of the wine or to its colour?}

At this point, it is worth noting that given the constraints of glassware provisioning at the majority of large-scale tasting events, wines are normally served in standard issue clear wine glasses. As such, one might therefore legitimately wonder whether what people are actually matching to the music is not the taste, or bouquet, of the wine per se but rather its colour. Perhaps the dark red liquid in the glass (regardless of its taste or bouquet) just seems like a better match for a "heavier" piece of music. Such concerns become all the more worrying given Palmer et al.'s [16] results highlighting the existence of remarkably robust crossmodal correspondences between pieces of classical music and colour patches (see also $[17,18]$ ). ${ }^{8}$ At this point, it is often suggested that serving wine in black tasting glasses, so that its colour is no longer visible, would solve this potential problem. ${ }^{9}$ It is, however, important to stress that black wine glasses do not completely solve the issue of participants matching music with colour. Bear in mind here only the fact that the majority of people can probably imagine the colour (red vs. white) of the wine when tasting, even when the wine's actual colour has been obscured (cf. $[19,20])$. Thus, even if one were to use black tasting glasses, one's participants might still simply be basing their crossmodal matches on the imagined colour of the wine.

One of the challenges, then, moving forward will be to repeat these kinds of demonstrations with wines that are more similar (perhaps starting with the same colour, then the same grape, and so on). Removing any obvious colour differences would certainly be an important first step in helping to rule out a colour-based account of many of the wine-music matching results that have been reported to date.

\section{Interim summary}

To summarize what we have seen so far, regular drinkers do indeed appear to feel a certain affinity between specific wines and music. As such, all the wine writers who have used musical metaphors and analogues to describe a wine can probably rest assured that most people really do experience crossmodal correspondences between music and wine $([11,14,15]$; see also $[21]) .{ }^{10}$ Given what we have seen already, there are probably sufficient grounds to argue against Paul White's suggestion of a few years ago: “...I've rarely resorted to describing wines through musical terminology (staccato, crescendo, rubato, riff, etc.) or made direct associations between tunes and individual wines: "This Riesling is so middle-period Nirvana..." That's not to say those aren't valid expressions; it's just not the way I've sensed wine and tried to lay it out in words. To be frank, I've always feared how easily that sort of discussion can end up sounding trite or pretentious or simply slink off into esoteric nonsense." ([22], p. 122).

One interesting question here that has yet to receive an adequate answer is, "On what basis exactly are people rating a particular piece of music as being a good match for a given wine?" It is certainly the case that they often feel confident about their choice (i.e. it is not as if the question appears meaningless and that people feel that they are being forced into trying to guess wildly). In the case of the most stark contrast (i.e. between a light white wine and a heavy red, say), most people seem both comfortable of their own responses and also confident that other people will share their intuitions as well (cf. [23]). Is it perceptual similarity that people are picking up on here [24-26], or could they simply be saying that one sensory experience complements the other in some way, like "bacon and eggs" or "sausage and mash" [27]? Notice, here, how the latter suggestion would not necessitate that the music and wine be perceived as in any way similar; the pair only needs to be judged as going (or pairing) well together (in much the same way as certain wines are said to pair particularly well with certain foods; think Chablis and seafood for a "like-with-like" example, or sauternes and foie gras, for a contrasting one; cf. [28]). ${ }^{11}$

Interestingly, when, at a recent workshop in Oxford [29], the attendees were asked on what basis they made their wine-music matches, a small number of people reported simply matching the wine they liked better with the music they liked better (i.e. a hedonic matching account). However, by far, the majority chose a common metaphorical attribute that the wine and music both had in common, such as robustness, lightness, complexity, sharpness or richness.

It is worth stressing that we have only reported on the results of the wine-music matching events that we are 
more familiar with. We are, though, aware that numerous other music-wine matching events have been taking place around the world over the last couple of years: from events organized by enologist and food engineer Stella Vassiliki in Crete, Greece, to the aforementioned music and wine matching workshop held in Oxford with Ben Houge [29]. A number of wine-music events have also been hosted in major cities such as London $[14,30,31]^{12}$ and Munich [31]. Clark Smith has also been active in this area, giving a presentation at the 2007 Australian Wine Industry Technical Conference (AWITC) in Adelaide exploring recent advances in cognitive musicology and speculating on parallels in wine sensory perception (see http://www.postmodernwinemaking.com/wine-and-music). Over the last few years, Martin Sachse-Weinert [32] has had more than 3000 people, including many wine industry professionals, matching music and wine. Meanwhile, Jo Burzynska working out of Christchurch, New Zealand (http://stanierblackfive.com/oenosthesia-sound-and-wine/; http://auricle.org.nz/mishearings-by-jo-burzynska/), has also been very active in this field. All - in - all, there has been a real explosion of interest in such wine-music matching events in recent years.

While public tasting events such as those that have been described so far undoubtedly provide an engaging means of demonstrating an association between music and wine, one might wonder what is currently known about the aspects of sound/music (such as pitch, timbre or instrument type, roughness, and tempo) that correspond with which tastes, aroma/bouquet, flavour and possibly also mouthfeel characteristics (such as astringency/grippiness or viscosity/alcohol) of wine. The good news here, as hinted at by the above description of the music-wine pairings utilized in Wang and Spence's [11] study, is that there is actually plenty of published research to build on.

\section{Establishing the correspondences between taste/flavour and audition}

Now, in terms of picking music to match a wine, there are a number of results concerning crossmodal matches to basic tastes, aromas (including those typically found in wine) and flavours that can be used to guide one's decisions as to the music that is likely to go especially well with a given wine. But, of course, music varies in so many dimensions: think only of timbre, brightness, rhythm, articulation (legato, staccato) and so on. But then again so does wine, think only of aroma (first and second nose), taste, mouthfeel, flavour and so on. One could all too easily feel at a loss as to where to begin. Here, we are going to start with the matching of music to the basic tastes (by which we mean sweet, sour, bitter, salty and umami) that may be present in wine. Here, a large body of empirical research shows that sweetness tends to be matched with sounds that are higher in pitch, with the sound of the piano, with music that is legato in articulation, and with consonant harmonies $[12,13]$. By contrast, sourness tends to be matched with very high pitch sounds, fast tempo, and dissonant harmonies instead $[12,13] .{ }^{13}$ Bitterness is matched with sounds that are lower in pitch and more likely to be brassy [33, 34]. While some writers have tasted saltiness or a hint of umami in the wines that they have tried [35], ${ }^{14}$ such descriptions are rare. Hence, for the moment, they can be safely ignored here. (Though rest assured that the musical parameters that are associated with these basic tastes have been established; see [33, 36, 37]). Indeed, at a recent conference, one Japanese researcher gave the following musical metaphor for umami: "Umami is just like the bass note in music. No one listens only to the bass, but the sounds of the bass notes has an important role to give depth and presence to music. Umami likewise creates balance and harmony in dishes." $[38] .{ }^{15}$

Some years back, Crisinel and Spence [39, 40] conducted a series of experiments in which the participants (tested in the laboratory) had to pick a musical note (one of 13 sustained musical notes from $\mathrm{C} 2(64.4 \mathrm{~Hz})$ to $\mathrm{C} 6$ $(1046.5 \mathrm{~Hz})$ in intervals of two tones) and pick a class of musical instrument (piano, strings, wind and brass) to go with a variety of basic tastes and with each of 20 of the key aromas (presented orthonasally) commonly found in wine (including almond, apple, apricot, blackberry, caramel, cedar, dark chocolate, cut hay, green pepper, honey, lemon, liquorice, mushroom, musk, pepper, pineapple, raspberry, smoked, vanilla and violet). The participants were seated in front of a virtual keyboard that allowed them to play each one of the 52 possible sounds (i.e. 4 instruments $\times 13$ pitches) in order to find the best match. The results demonstrated that for a number of the tastes and aromas, the participants were consistent in terms of the notes and instruments that they felt went especially well together. ${ }^{16}$ So, for example, fruity notes such as apricot, blackberry, and raspberry were all matched with higher (rather than lower) musical notes, and with the sounds of the piano and often also woodwind instruments, rather than with brass or string instruments (see Figs. 2 and 3). In contrast, lower pitched musical notes were associated with musky, woody, dark chocolate, and smoky aromas, bitter tastes and brassy instruments. Such results tie in with Kent Bach's ([41], p. 27) suggestion that: "Taking a sip of wine, at least a wine worth talking about, is like hearing the sound of a sustained, musical chord."

One limitation with the instrument matching results that have been published to date, though, is that the participants have normally been forced to choose between 


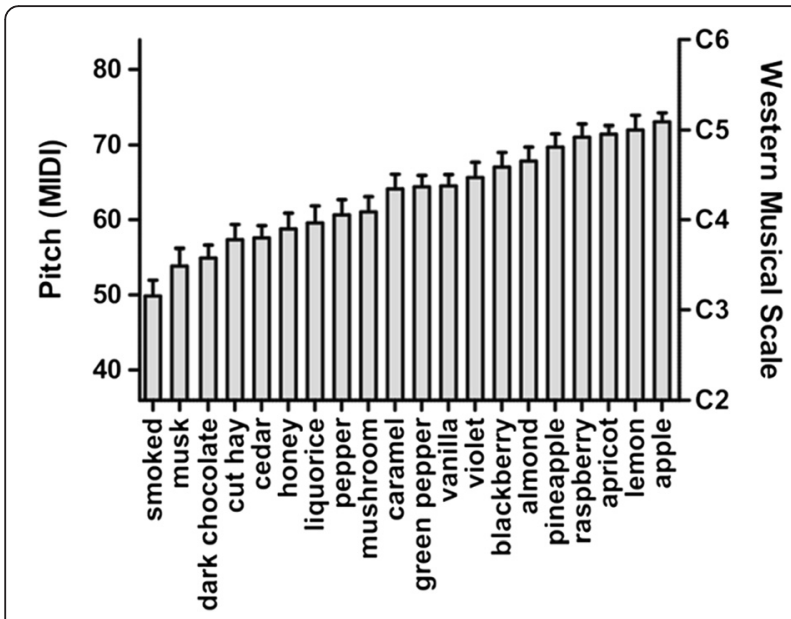

Fig. 2 Crossmodal correspondences between typical wine aromas and musical notes and instrument types, established by Crisinel and Spence [40]. Graph shows mean pitch matched to each odour. Musical instrument digital interface (MIDI) note numbers were used to code the pitch of the chosen notes. Western musical scale notation is shown on the right-hand $y$-axis. Visual inspection of the figure reveals that high-pitched notes were preferred for fruit aromas (reprinted with permission)

four classes of instrument. What sort of matches would people come up with if given free choice of the instrument to match a given taste, aroma, flavour or even wine $?^{17}$ Other useful results when it comes to matching music to wine comes from research by Bronner et al. [13] funded by Symrise (an international flavour house). These researchers established certain musical parameters that paired especially well with citrus and vanilla aromas (see Table 1), two notes that one often finds in wine. Note that it is something of an open question here whether it is really the aroma that is captured musically or the sour and sweet tastes that are so often associated with citrus and vanilla aromas, respectively (e.g. see [42]). Indeed, potentially relevant here, somewhat

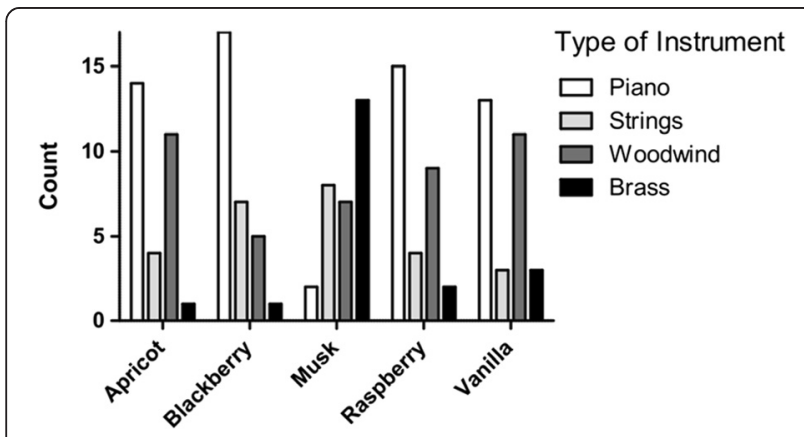

Fig. 3 Crossmodal correspondences between typical wine aromas and types of musical instrument, established by Crisinel and Spence [40]. Visual inspection of the figure highlights how the "sweet" smells [42] were associated with the sound of the piano while musk and bitter aromas (e.g., dark chocolate, not shown) were associated with the sound of a brass instrument instead (reprinted with permission)
Table 1 Musical matches for the flavours of citrus and vanilla established by Bronner et al. [13] (table reprinted from Spence [1] with permission)

\begin{tabular}{lll}
\hline $\begin{array}{l}\text { Musical parameters matching the flavours of citrus and vanilla } \\
\text { parameter }\end{array}$ & Orange & Vanilla \\
Timber & $\begin{array}{l}\text { Bright, fairly sharp and } \\
\text { rough }\end{array}$ & $\begin{array}{l}\text { Soft, dull, not sharp, } \\
\text { not rough }\end{array}$ \\
Ambitus & Middle range to big & Small \\
Articulation & $\begin{array}{l}\text { Staccato, accentuated, } \\
\text { dynamic }\end{array}$ & $\begin{array}{l}\text { Legato, even, less } \\
\text { dynamic }\end{array}$ \\
Rhythm & Syncopated & Even, not syncopated \\
Melody & Middle range, to steps, & Small-interval \\
& large step intervals & consonant \\
Tempo & Lively and fast (vivace) & Rather slow (adagio) \\
\hline
\end{tabular}

stronger crossmodal associations were typically obtained by Crisinel and Spence for basic tastants rather than for odorants/flavours.

\section{Loudness}

One attribute of music that has not been mentioned yet is loudness. One might wonder whether there is a crossmodal correspondence between the loudness of the music (or sound) and the intensity of the taste, aroma or flavour. Indeed, we have recently conducted a series of experiments to show that people do indeed, match more intense tastes with louder sounds (see [43]). A similar idea was also captured recently by Nick Ryan, a BAFTA award-winning musician and composer (who is also a synaesthete) who created a series of soundscapes to accompany a set of three wines tasted at the 2015 Streets of Spain wine event. He chose a louder composition to go with Campo Viejo's Rioja Gran Reserva because, in his words, "The Gran Reserva is a deeper louder sound." ${ }^{18}$ (quoted in [44], p. 7).

However, one potential problem here is that depending on one's sensitivity to bitter compounds, such as PROP (6-n-propylthiouracil), people have been shown to match a very different volume of sound to a given taste intensity (see $[43,45]) .{ }^{19}$ Intriguingly, however, these individual differences tend to be most pronounced for certain bitter-tasting compounds, though they certainly do also impact on the perception of other tastes and also alcohol [46]. According to such results, then, loudness may provide a better correspondence (or match) for the intensity of sweetness, sourness or aroma/bouquet of a wine than for the intensity of bitter sensations, given the large individual differences in this regard. Of course, just because the between-subject variance is larger when it comes to loudness-bitterness matching, that does not mean that loudness is not a good index of perceived bitterness intensity, but it does mean that it may be difficult to use 
loudness as a signifier of bitterness in a way that is equally meaningful to all.

\section{Sparkling wine}

It is easy here to imagine how the effervescence (or mouthfeel characteristics) that are associated with a sparkling wine, think champagne, cava or prosecco might give rise to somewhat different musical associations than is the case for still wines. For example, fine champagne gives Fretter ([47], p. 99) the same feeling as the scherzo in Beethoven's string quartet in C sharp major. Or take the following quote from Paul White ([22], pp. 122-123) writing in The World of Fine Wine: "...it's hard to think of music that is more transparently effervescent than Steve Reich's Octet and Music for Large Ensemble. Both have textural aspects strongly reminiscent of Champagne. Bouncing along optimistically, motives advance and recede like the frothy mousse of a freshly poured glass: bubbles forming and popping with little explosive jolts, instantly replaced by others" ${ }^{20}$ We had thought it possible that the sound of the rapid plucking of harp strings might correspond particularly well with the distinctive sensation of bubbles of carbonation popping on the taster's tongue. However, when we have assessed this informally at wine events, our audience have not really concurred on the appropriateness of such a match. ${ }^{21}$ Instead, perhaps we should just use Nick Ryan's suggestion of using the sound of mung beans falling on a plastic tray to represent the sound of cava (see [44]). More research is definitely needed on this score, to determine the music correspondences for carbonation.

\section{On higher level correspondences between wine and music}

Wine writers often anthropomorphise wines; for instance, a young sauvignon blanc might be described as a beautiful bride while a Bordeaux red might be descried as a well-tailored gentleman [48]. These descriptions might not, however, be quite as strange or idiosyncratic as they first appear. Watt and Quinn [49] have shown that participants reliably associate higher level adjectives (such as young/old, male/female, day/night) with certain pieces of music (see also [50]). In their study, participants heard four pieces of 10-s music excerpts; for each piece, they were asked to make 12 two-alternative forced-choice responses, choosing one adjective from each of 12 pairs of contrasting adjectives. We recently replicated Watt and Quinn's study but with glasses of wine instead of musical excerpts. Participants $(N=50)$ tasted two glasses of wine, a New Zealand Sauvignon Blanc and a French Malbec, ${ }^{22}$ and for each wine, they were presented with the same 12 pairs of adjectives as in Watt and Quinn's study (see Table 2) and asked to choose one adjective out of each pair that best matched the wine. To ensure that our participants were not matching adjectives to wine on the basis of the wines' colour, the participants were blindfolded while they tasted each wine, and the wine glass was removed before they took off the blindfolds to do the adjective matching task (though, of course, as mentioned earlier, we could not completely remove the influence of colour as our participants may still have imagined the colour of the wine (cf. [19]). The results revealed that participants chose the adjectives female, good, young, gentle, sweet, narrow, day and fast significantly more often for the Sauvignon Blanc and old, smooth, sour, night and slow significantly more often for the Malbec. One can imagine this type of results inspiring composers to come up with new wine compositions that somehow match higher level descriptive or analytic characteristics of the wine.

\section{On crossmodal correspondences between wine and vocal sounds}

The focus so far in this review, and in the literature more generally, has very much been on instrumental music. As such, one area that has not really been touched upon as yet is the existence of any crossmodal matches that might exist between vocal sounds and taste/wine. However, it is clear that different speech-like sounds are consistently matched to different tastes ([51]; see also [52]). In addition, given the higher level matching mentioned above, such as male/female and young/ old, one could easily imagine how there would be robust crossmodal correspondences between vocal sounds and wine. This is, then, undoubtedly another important area for researchers interested in the links between music and wine to explore in the coming years.

Table 2 Results showing participants' choices in the wineadjective matching task. Adjectives shown in italics were chosen significantly more often than their paired counterparts $(p<.05)$

\begin{tabular}{llll}
\hline Sauvignon blanc & & Malbec & \\
\hline Female & Male & Female & Male \\
Good & Evil & Good & Evil \\
Old & Young & Old & Young \\
Gentle & Violent & Gentle & Violent \\
Sad & Joyful & Sad & Joyful \\
Pleased & Angry & Pleased & Angry \\
Dull & Bright & Dull & Bright \\
Prickly & Smooth & Prickly & Smooth \\
Sweet & Sour & Sweet & Sour \\
Narrow & Wide & Narrow & Wide \\
Day & Night & Day & Night \\
Fast & Slow & Fast & Slow \\
\hline
\end{tabular}




\section{Interim summary}

Over the last few years, a number of researchers have started to systematically assess the musical parameters that people associate with basic tastes, aromas/bouquets, flavours and even the mouthfeel characteristics of wine. Hence, if one has an interesting wine, there are probably already guidelines out there regarding the likely qualities that one should be looking for in music to provide a good match (at least in terms of music that corresponds crossmodally). Here, it is perhaps also worth noting that rather than being content with picking music off the shelf to match a wine (or some attribute of that wine), some researchers have now even started to compose music in order to convey a specific taste (e.g. [37, 53]) or aroma (e.g. [13, 21]). After all, music often changes over time-just think of the stylistic changes one gets in Queen's "Bohemian Rhapsody" or in Mozart's Piano Sonata No. 12 in F Major (K332), which varies between major and minor mode (both examples from [54]). As such, it can sometimes be a challenge with different sections of a piece of music corresponding to different tastes/flavours. Ideally, at least according to sound artist and composer Ben Houge, what one wants is something more akin to video game music that is forever evolving but always stays the same [29]. Alternatively, it is easy to imagine that some wine and music matches may be facilitated by how they evolve over time. Note here that the Temporal Dominance of Sensations (TDS) is a promising method from the field of sensory science that could potentially be used to analyse the perceived properties of both music and taste/flavour as they evolve through time [55].

\section{Synaesthesia, oenesthesia and crossmodal correspondences}

Having demonstrated the existence of robust crossmodal mappings between music, or musical parameters, and tastes, aromas, flavours and wines, the next question that comes to mind here is how best to account for such a phenomenon, that is, how best to account for that feeling of rightness that can accompany the pairing of wine with the appropriate music? Some have suggested synaesthesia, others oenesthesia, but as we hope to convince you here, crossmodal correspondences may represent a more appropriate and useful way to think about these surprising cross-sensory matches between seemingly unrelated stimuli that we all (or at least most of us) share.

\section{On the seductive allure of synaesthesia}

One popular suggestion here is that these crossmodal matches between music and wine must reflect some sort of synaesthesia [31], or "oenesthesia”, as Jo Buzynska has suggested. However, while there are undoubtedly synaesthetes who do literally experience tastes and flavours on hearing particular sounds, it is important to note that such individuals are exceedingly rare [51]. What is more, the taste concurrents that the synaesthete experiences on hearing a particular sonic inducer tend to be idiosyncratic. What this means, in practice, is that they are unlikely to be shared by another synaesthete, nevermind by the public at large. So, for instance, a few years ago, Swiss researchers came across a synaesthete who reported experiencing specific tastes on hearing different musical tone intervals: the sound of a minor second, for example, giving rise to a sour taste on the tongue [56]. Another famous synaesthete, the Russian mnemonist (someone with an extremely impressive memory) "S", described back in the 1960 s by Luria ([57], p. 23), experienced a wide variety of different taste/flavour sensations in response to hearing different sounds: When presented with a $50-\mathrm{Hz}$ tone (for musicians, the note that this corresponds to is approximately G1), he experienced a taste he likened to sweet and sour borscht "a sensation that gripped his entire tongue". Meanwhile, listening to a $3000-\mathrm{Hz}$ tone (i.e. close to a G7) would evoke "an ugly taste-rather like that of a briny pickle" instead. Or take the synaesthetic composer Nick Ryan, who we came across earlier. For him, "acidic wines with high tannin content sound high-pitched, while sweet fruity varieties need more harmonious and complex compositions." ([44], p. 7).

That being said, a number of the synaesthetic concurrents mentioned above do actually turn out to be similar to what has been shown experimentally in the case of the crossmodal correspondences shared by the majority of us. ${ }^{23}$ For instance, while a minor second gave rise to a sour taste for one sound-taste synaesthete, it has been shown that, when presented with consonant melody harmonized with major and minor thirds and a dissonant melody harmonized with minor seconds, participants associated the dissonant melody with greater sourness and actually rated juice samples as tasting more sour than sweet when listening to the dissonant music [58]. The synaesthete "S", who associates G7 with the taste of a briny pickle, may also be picking up on something shared, as sourness has been shown to correspond with high pitch [12, 43, 59]. Finally, participants at a musicwine tasting event held in Oxford rated wines as tasting more acidic when listening to a high-pitched Debussy piano piece and more fruity when listening to a melodious Rachmaninoff cello piece [11], which certainly agrees with Nick Ryan's assessments of wines. That said, the important point to remember here is that not all idiosyncratic concurrents have their equivalent in the crossmodal correspondences; for example, while " $\mathrm{S}$ " experienced a low G1 tone with sweet and sour tastes, it's been shown that most non-synaesthetes actually associate low tones with bitter tastes instead [12, 43, 59]. 
Thus, while synaesthesia is undoubtedly a fascinating empirical phenomenon (especially for the light it shines on individual differences in perception), the surprising associations that the very small number of auditorygustatory synaesthetes experience between sound and taste have only limited relevance when it comes to trying to find cross-sensory matches that work, or are shared, by large groups of individuals (see [60]). Furthermore, our worry is that while the label "oenesthesia", just like synaesthesia, is undoubtedly a catchy one, there is a very real danger here of blurring the important distinctions between the genuine synaesthesia experienced by a very small number of individuals, and the crossmodal correspondences (see below) experienced by us all. Ultimately, using the moniker, "synaesthesia" [31], or its derivative "oenesthesia", while undoubtedly likely to capture the attention of the public/media [44], risks misdirecting their burgeoning interest in all things multisensory in the wrong direction.

Rather, we would like to argue that the crossmodal matches that have been reviewed here appear to be consistent across groups of observers and consist more of a feeling of appropriateness (that two complex stimuli, wine and music, go well together) than an actual experience of a gustatory concurrent on hearing the music or literally hearing the music on tasting the wine. For all of these reasons (and more; see [60], for a review of all the differences that have been outlined to date), we would like to suggest that in our opinion, what explains the crossmodal matches that have been reviewed here is not synaesthesia but rather crossmodal correspondences. Crucially, crossmodal correspondences are not just a weak form of synaesthesia (as has been suggested by [3]) but are a qualitatively different phenomena.

\section{Crossmodal correspondences}

Crossmodal correspondences have been defined as the surprising (at least when we initially find out about them) crossmodal associations between features, attributes or sensory dimensions in different sensory modalities. So for example, most people will associate brighter visual stimuli with higher pitched sounds, higher pitched sounds with higher elevations in space, and sweet tastes with round forms. Crossmodal correspondences tend to be shared across individuals and are experienced as a feeling of going together, or matching, without any necessary sensory concurrent (which has been defined as a core attribute of synaesthesia proper). While some influential researchers have been tempted to characterize crossmodal correspondences as "a weak form of synaesthesia" [3], we have argued at length elsewhere that despite some superficial similarities, these two phenomena are qualitatively quite different (see [60]).
It is worth noting that a number of putative underlying causes have been put forward to help explain the crossmodal correspondences (see [4] for a review). On the one hand, certain correspondences reflect the internalization of the statistical regularities of the environment, such as the fact that high-pitched sounds do generally tend to come from higher in space (see [52], for recent empirical evidence on this score). It is unclear how relevant this account is to the wine-music matching case-are we really any more likely to listen to a particular kind of sound/music while drinking a particular type of wine? An argument may perhaps be made for expensive wines that are often drunk in high-end restaurants with subdued classical or light jazz music (at least, this would only pertain to those individuals with a hefty enough bank account to make it a statistical regularity) or for "ethnic" wines consumed in ethnic restaurants (e.g. just think Pavarotti and a glass of Chianti at the local Italian restaurant). An interesting case could be made here for a cross-cultural study with two populations where the same wine might have very different meanings-and perhaps very different musical matchings (for instance, the same bottle of Bordeaux might be an everyday occurrence for those living in Bordeaux, whereas claret has more of an upper-class connotation in the UK).

A second account is structural in nature (see [61]). It turns out that increasing stimulus intensity is coded by increased neural firing, regardless of the sensory input under consideration [62]. As such, there might be a common code for matching sensations in the way in which the brain codes information. Remember here the crossmodal matching of loudness with taste/flavour intensity we came across earlier [43]. It just might provide evidence of a structural correspondence. Though given the speed of statistical learning, it is always hard to rule that out as a potential account.

A third account of crossmodal correspondences is in terms of the shared language we use to describe different kinds of sensations [63]. Note here only how we might use the same descriptor "sharp" to describe a 10,000- $\mathrm{Hz}$ tone and also a citrus note in a wine aroma. Furthermore, we have seen how people associate metaphoric adjectives, such as male/female [49] or powerful/subtle [64] with both music and wine. The pervasiveness of such linguistic similarities may account for many instances of wine-music correspondences/matching.

As we have seen already, people tend to match more intense tastes with louder sounds, which is at least consistent with (but by no means necessitated by) the structural account. We also use similar language and descriptors to talk about both music and wine (see $[49,64])$. Indeed, the term sweet is used both to describe a basic taste, but also certain aromas, such as vanilla and strawberry, and a certain musical style, 
thus potentially supporting a semantic account. Finally, there is evidence to suggest that we associate music and wine based on emotions.

There is growing evidence in support of the existence of affective correspondences [65, 66], mediated by a common feeling engendered by, or associated with, a particular pair of stimuli (cf. [36]). Indeed, a number of studies have already highlighted the role of emotion in mediating crossmodal correspondences between colour and music [16-18], colour and aroma (e.g. [67]), shape and taste (cf. [68]), and also between basic taste and sound [43]. Therefore, why not think that emotion also mediates the mapping between music and wine. After all, as Gray ([69], p. 2) suggests, "Red wines need either minor key or they need music that has negative emotion. They don't like happy music...Cabernets like angry music." Elsewhere, one finds Paul White ([22], p. 121) writing that: "...wine and music have a long and natural emotional association". And winemaker and wine technologist Clark Smith has argued that "we associate different wine types with different moods, just as we do with music. Cabernets are angry, Pinots romantic, Rieslings cheerful" (quoted in [70] see also http://www.postmodernwinemaking.com/wine-and-music). That said, when talking about affective correspondences, it is important to distinguish between the emotion that the listener attaches to a piece of music (or a glass of wine) and the emotional impact that listening to a piece of music (or drinking a wine) can have on the listener $[54,71]$. Both could, of course, provide legitimate grounds for pairing wine and music.

One can, we think, certainly envision how the various crossmodal correspondences between wine and music that have been highlighted in this review might fall into one or more of the four categories outlined above (note here also that the various explanations, or accounts, should certainly not be thought of as mutually exclusive). Semantic correspondences might, for example, turn out to be based on the statistical regularities of the environment. It will be the job of future research to determine what the most appropriate explanation (or, perhaps more likely, explanations) for each of the musicwine correspondences is.

\section{Conclusions}

As the research that has been reviewed here has hopefully made clear, the majority of people appreciate a natural affinity between certain pieces of music (or musical parameters, such as pitch and timbre) and particular wines (or the tastes, aroma, bouquet, flavour or mouthfeel characteristics thereof). The fact that the majority of us agree that bitter is lower in pitch, while sweet and sour are both higher in pitch, and the fact that this is merely a feeling (i.e. that there is no sensory concurrent) suggests, in our view, that what we are looking at here is better conceptualized in terms of crossmodal correspondences, rather than synaesthesia (despite the undoubted allure of the latter term). Having established the meaningfulness, then, of this kind of wine talk, we will, in a follow-up article, go on to look at how playing certain pieces of music (that either do, or do not, match, or correspond crossmodally) can, in turn, change people's ratings and hence presumably their experiences, of the wine that they happen to be tasting (see [6] for a review). In the meantime, it is worth noting that there are several other salient attributes of wine that have yet to be explicitly matched musically. These include tannins, viscosity, oak, alcohol level, and potentially also length (both in terms of mid-palate length, the duration of flavour as it is held in the mouth, as well as the length of flavour remaining in the mouth after the wine has been swallowed).

Another interesting question for future research concerns whether there are any regularities in the transition between the kinds of sound or music that are best paired with a wine as it ages [1]. It could well be imagined that the predictable softening of the tannins in a red wine, say, might be associated with a shift from brass to piano. Or perhaps the shift might take place more at the descriptive level, e.g. going from "young" to "old" music (i.e. one could here imagine pitting changing sensory correspondences against changing descriptive musical matches). A future project we are interested in would involve musically scoring a vertical selection of wines over different vintages to portray the life of the wine.

What is also worth noting is that all of the crossmodal matches that have been documented in this article were measured at just a single point in time. One might want to know, just like in synaesthesia, whether such correspondences are consistent over time for a given participant. Certainly, addressing that question in the case of wine can be a little tricky, given the fact that the wine itself will change (mature) as the wine ages. However, the only study that has been conducted thus far checking on the consistency (over time) of the crossmodal correspondences between auditory pitch and olfaction demonstrated a surprisingly high degree of consistency in the crossmodal matches between sound and orthonasal smell that regular (i.e. non-synaesthetic) participants made on being testing 2 years apart [25]. A related question here concerns whether the crossmodal matches between music and wine that have been established in western populations would extend to those coming from cultures that are very different. Here again, there has been nothing published in the world of wine-music matching. However, Knoeferle et al. [37] have recently shown how music composed in Germany to convey or be associated with the four basic tastes (sweet, sour, 
bitter and salty) can be decoded at almost the same level of accuracy (or consistency) by Indian participants, with a very different musical culture, than by western participants. So, while, at some level, one would expect that there must be salient cultural variation here, the results thus far do at least suggest that there may be some degree of cross-cultural consistency in these mappings as well, at least once one takes into account any differences in different people's hedonic responses to wine.

In closing, it is important to note that the matching of sounds and music to taste and flavour is not something that is restricted solely to the world of wine. (It is just that there always seems to be far more research on wine than any other food or beverage product, no matter what the question you are looking at. ${ }^{24}$ While the focus in this piece has been squarely on wine, there is absolutely no reason why what has been done so far in the sphere of wine-music matching could not also be done for a variety of other beverages, both alcoholic and nonalcoholic. Indeed, as it so happens, the very first studies to be published in the area of drink-music matching were actually conducted with Carlsberg beer [72, 73]. In his seminal work, Holt-Hansen demonstrated that people match Carlsberg Elephant lager to a higher pitch than regular Carlsberg lager (perhaps because of its higher alcohol content). More recently, writers such as Pete Brown have also been running events in which they take their audiences through an evening of beer and music matching ([74]; see also [75], for another example of beer-music matching).

\section{Endnotes}

${ }^{1}$ Indeed, one unconventional Australian wine writer, Mark Shield, has gone so far as to suggest that we forget about giving a number to evaluate a wine and instead simply score them by matching it to a particular piece of music instead ([76], pp. 25-27).

${ }^{2}$ Well, of course, it is not strictly true that no one compares wines to the visual arts (e.g. paintings). They do. It is just that this pairing of modalities seems to appear less frequently in wine writing than does the musicwine combination. In the popular Japanese wine manga Drops of God, wines are described in terms of famous paintings, pieces of music, landscapes, poetry, narratives, etc. Furthermore, Maurice Dimarino also makes pointby-point comparisons between wine and art attributes on his website; see http://www.mauricescru.com/2011/ 12/wine-and-art-pairing/\#.VcTK4WRViko. Going back in time, one also finds Fretter ([47], p. 99), suggesting that a particular painting by Hans Hofman brings to mind thoughts and feelings of a German wine trockenbeerenauslesen (cf. [77]).

${ }^{3}$ Synaesthetes are those rare individuals (though quite how rare no one can quite seem to agree) who tend to confuse their senses (or, better said, confuse their sensory experiences), most commonly seeing colours when they see or hear numbers or letters [78, 79]. A very small number of synaesthetes with auditory-gustatory synaesthesia experience vivid tastes and/or flavour sensations when they hear particular auditory or musical stimuli (see [56, 80-83], for a number of case studies).

${ }^{4}$ As to why wine writers go beyond the basics in their tasting notes, one has to realize the challenge of filling what may well be well over 1000 words on a single wine, as David Schildknecht is, for example, famous for doing, is no mean feat (see [84]; though see also [85]).

${ }^{5}$ The scientific study of the crossmodal matching of wine with music can be seen as analogous to, but a more complex version of, the growing body of research in which people (most often the participants in laboratory or online studies) have been tasked with trying to match basic tastes (or taste words)-bitter, sweet, salty, and sour-to one of a set of pre-selected pieces of music [33, 36, 37].

${ }^{6}$ The tasting notes for the white wine talked of grass, citrus, gooseberry notes, light body, and high acidity. For the red, the description talked of black fruit, oak, vanilla notes, medium body, medium acidity, and soft tannins. Note that the wines were selected to be very different from one another, in order to facilitate the musical matching.

${ }^{7}$ One possibility here is that people segment into sweet likers and those who are sweet neutral [86], and this might have been expected to add some variance to the matching results.

${ }^{8}$ In their study, nearly 100 participants from the USA and Mexico were presented with 18 pieces of classical orchestral music by Bach, Mozart and Brahms. For each piece of music, the participants had to pick one of 37 simultaneously presented colour patches. The results revealed that lighter colours were shown to be matched fast tempo, darker colours with music having a slower tempo.

${ }^{9}$ In fact, we have conducted a pilot study in which 19 participants tasted a New Zealand sauvignon blanc and an Argentinian malbec in black wine glasses. They heard a piece of organ music-Humphrey Clucas' Prelude from Coldrige Baroque-and a piece of harp music-Germane Taiileferre's Harp Sonata Movement III. The organ and harp were chosen because a previous wineinstrument matching study involving the same two wines had highlighted an overwhelming matching of organ with the Malbec and harp with Sauvignon Blanc (the participants were asked to pick an instrument from eight possible categories: piano, choir, strings, woodwind, organ, harp, guitar and brass). The participants had to rate each wine-music combination in terms of matching and liking. For the Malbec, there was a 
significant different in matching ratings between the organ and harp music ( $M=4.21$ vs. 2.74 , on a scale from $1-7$, where higher values indicate a better subjective match, $p$ $=.008$ using related-samples Wilcoxon signed rank test), with the organ being judged a better match than the harp. However, we did not, however, see any differences in crossmodal matching ratings for the Sauvignon Blanc.

${ }^{10}$ And if that was not enough Charters and Pettigrew ([87], p. 126) have noted that "informants considered that the consumption of wine shows some similarities to the appreciation of 'pure' art forms - especially music".

${ }^{11}$ Of course, there are alternative views of the interaction of wine and music as captured by the following from Doug Frost (MW): "So I don't want music and wine to match up; I want them to talk to each other. They may agree; they may argue. Sometimes they don't speak at all; they just yell past each other. That's cool too." (quoted in [32]).

${ }^{12}$ The champagne house Krug organized a 4-day event in April 2014, together with the London Philharmonia Orchestra who played via digital installation/link "The Rites of Spring" to celebrate one of their champagnes. The aim, apparently, was to highlight the "parallels between conducting a symphony orchestra and composing Krug Grande Cuvée" (King, 2014).

${ }^{13}$ Back in 1855, Hector Berlioz suggested that the sound of the oboe had an "acid-sweet voice".

${ }^{14} \mathrm{~A}$ number of white wines do have something of a saline quality! Think Picpoul, Muscadet and Albariño wines that usually are grown on coastal regions. And yeasty wines (wines that have been aged on yeast lees) like Chablis or Champagne can qualify as tasting of umami. This is perhaps clearest in high-quality champagne: Pol Roger's top cuvee, Winston Churchill, for example, tastes like golden unctuous chicken soup (albeit with fine bubbles).

${ }^{15}$ Incidentally, in taste-pitch matching tasks, participants do indeed match umami to a lower pitch range $[39,43]$.

${ }^{16}$ Though, in contrast to some of the wine-music matching demonstrations mentioned earlier, the participants in such studies often did feel especially confident in neither the matches that they make nor that the choices they make will necessarily be shared by others (cf. [88]).

${ }^{17}$ Unfortunately, the one time we tried this (i.e. free choice of instrument to match each of a selection of wines) with a bunch of professional philosophers in London, the data we obtained was not really usable. We had answers like "air guitar" and who knows what else. It remains to be ascertained whether this is a general problem with asking philosophers such questions or whether instead it reflects a more general problem with collecting meaningful data from such a free-response task.
${ }^{18}$ The three wines tasted were Campo Viejo cava brut, Rioja Reserva and Rioja Gran Reserva. The difference between the Reserva and Gran Reserva is that the former is aged 18 months in barrels plus a further 18 months in bottles. The Gran Reserva is aged for 24 months in barrels plus a further 36 months in bottles. This makes the Gran Reserva a more structured and complex wine [28].

${ }^{19}$ Such results have, in fact, been used to demonstrate that we all live in somewhat different taste worlds [89].

${ }^{20}$ Perhaps we should have taken inspiration from the music of Lawrence Welk, who was, until his death often referred to as the maestro of champagne music [90].

${ }^{21}$ In fact, in a pilot study $(N=10)$ at the lab with Krug Grand Cuvee, participants were given a choice between six musical pieces (same melody at three tempos (120, 180 or $240 \mathrm{bpm})$ ) and two instruments (harp or strings). We had expected that the participants would have chosen the fast harp piece as the best match, but, in fact, 6 out of 10 participants picked the medium tempo string rendition as the best match instead.

${ }^{22}$ The white wine was Goose Bay Sauvignon Blanc 2013 and the red wine was Calvet Cahors Malbec 2013. The tasting notes for the white wine talked of intense citrus fruit flavours and a crisp texture. For the red, the description talked of dark berry and spices aromas and a good balance between acidity and tannins.

${ }^{23}$ On occasion, of course, the synaesthete may, by chance, experience consciously the correspondence that is shared implicitly by the rest of us non-synaesthetes.

${ }^{24}$ And while the majority of sensory science research may well be conducted on wine (no matter whether it be studies of branding, labelling, pricing, packaging, etc.), there is a very real problem associated with the maturation of wines that does not affect any other beverage to quite the same degree. Just think about it, while the many music-wine matches described in the text were valid at the time the studies were conducted, should we now, some years later, wish to repeat the studies, then it is a little hard to know the extent to which any changes in the wine will have invalidated such crossmodal matches. Furthermore, the large number of bottles that may be corked [91-93], or display some other fault means that other drinks, that are most consistent over time, and less likely to be faulty, given they do not rely on worst bit of packaging ever invested (cf. [94]), the cork, might actually be a great way to proceed scientifically, moving forward.

Competing interests

The authors declare that they have no competing interests.

Authors' contributions

CS and Q(J)W wrote all parts of this review. Both authors read and approved the final manuscript. 


\section{Acknowledgements}

CS would like to acknowledge the AHRC Rethinking the Senses grant (AH/L007053/1).

\section{Received: 18 August 2015 Accepted: 5 December 2015} Published online: 14 December 2015

\section{References}

1. Spence C. Wine and music. World Fine Wine. 2011:29:112-9.

2. Johnson H. Wine: a life uncorked. London: Weidenfeld \& Nicolson; 2005.

3. Martino G, Marks LE. Synesthesia: strong and weak. Curr Dir Psychol Sci. 2001;10:61-5.

4. Spence C. Crossmodal correspondences: a tutorial review. Atten Percept Psychophys. 2011;73:971-95.

5. Spence C. On crossmodal correspondences and the future of synaesthetic marketing: matching music and soundscapes to tastes, flavours, and fragrance. In: Bronner K, Hirt R, Ringe C, editors. Audio branding academy yearbook 2012/2013. Baden-Baden: Nomos; 2013.

6. Spence C, Wang QJ. Wine \& music (II): can you taste the music? Flavour. 2015:4:33

7. Beardsley MC. Aesthetics: problems in the philosophy of criticism. New York: Harcourt, Brace \& Company; 1958

8. Tefler E. Food as art. In: Neill A, Ridley A, editors. Arguing about art: contemporary philosophical debates. 2nd ed. London: Routledge; 2002. p. 9-27.

9. Jones A. A far from vintage show as Callow uncorks the clichés. 2012 http://www.independent.co.uk/arts-entertainment/tv/features/the-week-inradio-a-far-from-vintage-show-as-callow-uncorks-the-clich-s-8269761.html. Accessed 3 Aug. 2015.

10. Helmholtz $\mathrm{H}$. The facts of perception. Selected writings of Hermann Helmholtz. Middletown: Wesleyan University Press; 1878.

11. Wang QJ, Spence C. Assessing the effect of musical congruency on wine tasting in a live performance setting. i-Perception. 2015;6:1-13.

12. Mesz B, Trevisan MA, Sigman M. The taste of music. Perception. 2011:40:209-19.

13. Bronner K, Frieler K, Bruhn H, Hirt R, Piper D. What is the sound of citrus? Research on the correspondences between the perception of sound and flavour. In: Tsougras C, Mavromatis P, Pastiadis K, editors. Proceedings of the ICMPC. Thessaloniki: ESCOM 2012 Joint Conference; 2012. p. 42-8.

14. Spence C, Richards L, Kjellin E, Huhnt A-M, Daskal V, Scheybeler A, et al. Looking for crossmodal correspondences between classical music \& fine wine. Flavour. 2013;2:29.

15. Spence C, Velasco C, Vanne M, Hopia A. Can you taste the music? In: Hopia A, Ihanus S, editors. 5D cookbook. Seinäjoki: KUMURU-project; 2014. p. 73.

16. Palmer SE, Schloss KB, Xu Z, Prado-Léon LR. Music-color associations are mediated by emotion. P Natl Acad Sci USA. 2013;110:8836-41.

17. Barbiere JM, Vidal A, Zellner DA. The color of music: correspondence through emotion. Empir Stud Arts. 2007:25:193-208.

18. Bresin R. What is the color of that music performance? P ICMC. 2005:2005(7):1-9.

19. Ballester J, Abdi H, Langlois J, Peyron D, Valentin D. The odor of colors: can wine experts and novices distinguish the odors of white, red, and rosé wines? Chemosens Percept. 2009;2:203-13.

20. Spence C. The color of wine-part 2. World Fine Wine. 2010;29:112-9.

21. Crisinel A-S, Jacquier C, Deroy O, Spence C. Composing with cross-modal correspondences: music and smells in concert. Chemosens Percept. 2013;6:45-52.

22. White P. Food of love: wine and music. World Fine Wine. 2008;21:120-3.

23. Koriat A. Subjective confidence in one's answers: the consensuality principle. J Exp Psychol Learn. 2008;34:945-59.

24. Marks LE. For hedgehogs and foxes: individual differences in the perception of cross-modal similarity. In: Ljunggren G, Dornic S, editors. Psychophysics in action. Berlin: Springer Verlag; 1989. p. 55-65.

25. Belkin K, Martin R, Kemp SE, Gilbert AN. Auditory pitch as a perceptual analogue to odor quality. Psychol Sci. 1997;8:340-2

26. Linscott TD, Lim J. Retronasal odor enhancement by salty and umami tastes. Food Qual Pref. 2016:48:1-10

27. Ahn YY, Ahnert SE, Bagrow JP, Barabasi AL. Flavor network and the principles of food pairing. Sci Rep. 2011;1:196.

28. Fielden C. Exploring the world of wines and spirits. London: Wine \& Spirit Education Trust; 2009.
29. Anon. The search for metaphorical matchings through wine and music. 2015. http://www.1855oxford.com. Accessed 12 Aug. 2015.

30. King J. Krug champagne redefines tasting notes with orchestra event. In: Luxury Daily. 2014. http://www.luxurydaily.com/krug-champagne-redefinestasting-notes-withorchestra-event/. Accessed 6 Aug. 2014.

31. Sachse-Weinert M. Voce:divino in München. Synästhesie in perfektion. [Voce: divino in Munich: Pure synaesthesia]. Weinfeder J. 2014;43:34-5.

32. Sachse-Weinert M. Wine \& musik: $2+2=5$ [Wine \& music: $2+2=5$ ]. Vortrag im Rahmen der Ringvorlesung "Weinwissenschaft" an der Johannes Gutenberg-Universität Mainz im Sommersemester. Presentation given on 4th July. 2012.

33. Wang QJ, Woods A, Spence C. "What's your taste in music?" A comparison of the effectiveness of various soundscapes in evoking specific tastes, i-Perception. 2015

34. Crisinel A-S, Cosser S, King S, Jones R, Petrie J, Spence C. A bittersweet symphony: systematically modulating the taste of food by changing the sonic properties of the soundtrack playing in the background. Food Qual Pref. 2012;24:201-4.

35. Hanni T. Umami taste in wine. 2008. http://www.timhanni.com/Umami taste_in_wine.doc. Accessed 23 June 2014.

36. Knoferle K, Spence C. Crossmodal correspondences between sounds and tastes. Psychon Bull Rev. 2012;19:992-1006.

37. Knoeferle KM, Woods A, Kappler F, Spence C. That sounds sweet: using crossmodal correspondences to communicate gustatory attributes. Psychol Market. 2015;32:107-20.

38. Nonomiya K. Science of umami taste: adaptation to gastronomic culture. Flavour. 2015;4:13

39. Crisinel A-S, Spence C. As bitter as a trombone: synesthetic correspondences in nonsynesthetes between tastes/flavors and musical notes. Atten Percept Psychophys. 2010;72:1994-2002

40. Crisinel A-S, Spence C. A fruity note: crossmodal associations between odors and musical notes. Chem Senses. 2012:37:151-8.

41. Bach K. Knowledge, wine, and taste: what good is knowledge (in enjoying wine)? In: Smith BC, editor. Questions of taste: the philosophy of wine. Oxford: Oxford University Press; 2007. p. 21-40.

42. Stevenson RJ, Boakes RA. Sweet and sour smells: learned synaesthesia between the senses of taste and smell. In: Calvert GA, Spence C, Stein BE, editors. The handbook of multisensory processing. Cambridge: MIT Press; 2004. p. 69-83.

43. Wang QJ, Wang S, Spence C. "Turn up the taste": assessing the role of taste intensity and emotion in mediating crossmodal correspondences between basic tastes and pitch. Chem Senses. submitted.

44. Knapton S. Why sparkling wine sounds like beans falling on a plastic tray. Daily Telegraph. 2015;2.

45. Marks LE, Stevens JC, Bartoshuk LM, Gent LF, Rifkin B, Stone VK. Magnitudematching: the measurement of taste and smell. Chem Senses. 1988;13:63-87.

46. Duffy VB, Peterson JM, Bartoshuk LM. Associations between taste genetics, oral sensation and alcohol intake. Physiol Behav. 2004;82:435-45.

47. Fretter WB. Is wine an art object? J Aesthet Art Critic. 1971;30:97-100.

48. Agi T, Okimoto S. Les Gouttes de Dieu. Grenoble: Glénat; 2011.

49. Watt R, Quinn S. Some robust higher-level percepts for music. Perception. 2007:36:1834-48.

50. Baraldi FB, De Poli G, Roda A. Communicating expressive intentions with a single piano note. J New Music Res. 2006:35:197-210.

51. Simner J, Cuskley C, Kirby S. What sound does that taste? Cross-modal mappings across gustation and audition. Perception. 2010;39:553-69.

52. Parise CV, Knorre K, Ernst MO. Natural auditory scene statistics shapes human spatial hearing. Proc Natl Acad Sci U S A. 2014;111:6104-8.

53. Mesz B, Sigman M, Trevisan MA. A composition algorithm based on crossmodal taste-music correspondences. Front Hum Neurosci. 2012;6:71.

54. Crawshaw A. How musical emotion may provide clues for understanding the observed impact of music on gustatory and olfactory perception in the context of wine-tasting. 2012. Unpublished manuscript.

55. Pineau N, Schlich $P$, Cordelle $S$, Mathonnière $C$, Issanchou $S$, Imbert $A$, et al. Temporal dominance of sensations: construction of the TDS curves and comparison with time-intensity. Food Qual Pref. 2009;20:450-5.

56. Beeli G, Esslen M, Jancke L. Synaesthesia: when coloured sounds taste sweet. Nature. 2005;434:38

57. Luria AR. The mind of a mnemonist. Cambridge: Harvard University Press; 1968. 
58. Wang QJ, Spence C. "Striking a sour note": assessing the influence of consonant and dissonant music on taste perception. Multisens Res. 2015;29:195-208.

59. Crisinel A-S, Spence C. Implicit association between basic tastes and pitch. Neurosci Lett. 2009;464:39-42.

60. Deroy O, Spence C. Weakening the case for 'weak synaesthesia': why crossmodal correspondences are not synaesthetic. Psychon Bull Rev. 2013;20:643-64.

61. Marks LE. The unity of the senses: interrelations among the modalities. New York: Academic Press; 1978.

62. Stevens SS. On the psychophysical law. Psychol Rev. 1957;64:153-81.

63. Walker P. Cross-sensory correspondences and naive conceptions of natural phenomena. Perception. 2012;41:620-2.

64. North AC. The effect of background music on the taste of wine. $\mathrm{Br} J$ Psychol. 2012;103:293-301.

65. Collier GL. Affective synaesthesia: extracting emotion space from simple perceptual stimuli. Motiv Emotion. 1996;20:1-32.

66. Deroy O, Crisinel A-S, Spence C. Crossmodal correspondences between odors and contingent features: odors, musical notes, and geometrical shapes. Psychon Bull Rev. 2013;20:878-96.

67. Schifferstein HNJ, Tanudjaja I. Visualising fragrances through colours: the mediating role of emotions. Perception. 2004;33:1249-66.

68. Velasco C, Woods AT, Deroy O, Spence C. Hedonic mediation of the crossmodal correspondence between taste and shape. Food Qual Pref. 2015;41:151-8.

69. Gray WB. Music to drink wine by: Vintner insists music can change wine's flavors. San Francisco Chronicle. 2007 November;11.

70. Burzynska J. The sweet rhythms of Italy's vineyards. In: The New Zealand Herald. 2012. http://www.nzherald.co.nz/jo-burzynska/news/article.cfm?a_ id=656\&objectid=10828652. Accessed 5 Aug. 2015.

71. Bredie WLP, Tan HSG, Wendin K. A comparative study on facially expressed emotions in response to basic tastes. Chemosens Percept. 2014;7:1-9.

72. Holt-Hansen K. Taste and pitch. Percept Mot Skills. 1968;27:59-68.

73. Holt-Hansen K. Extraordinary experiences during cross-modal perception. Percept Mot Skills. 1976;43:1023-7.

74. Brown P. Ale, ale, rock and roll! Word Magazine. 2012;3:28-9.

75. Anon. Beer and music evening. 2015. http://auricle.org.nz/beer-and-musicevening-with-harringtons/. Accessed 4 Aug. 2015.

76. Mitchell $E$, Mitchell $B$. The psychology of wine: truth and beauty by the glass. Oxford: Praeger; 2009.

77. Walker R. The effects of culture, environment, age, and musical training on choices of visual metaphors for sound. Percept Psychophys. 1987;42:491-502.

78. Cytowic RE, Eagleman DM. Wednesday is indigo blue: discovering the brain of synesthesia. Cambridge: MIT Press; 2009.

79. Harrison J. Synaesthesia: the strangest thing. Oxford: Oxford University Press; 2001.

80. Colizoli O, Murre JM, Rouw R. A taste for words and sounds: a case of lexical-gustatory and sound-gustatory synesthesia. Front Psychol. 2013;4:775.

81. Ferrari GC. Un nuovo caso di sinestesia uditivo-gustativa [A new case of auditory-gustatory synaesthesia]. Rivista di Psicologia. 1910;6:101-4.

82. Hanggi J, Beeli G, Oechslin MS, Jancke L. The multiple synaesthete E.S.: neuroanatomical basis of interval-taste and tone-colour synaesthesia. Neurolmage. 2008;43:192-203.

83. Pierce AH. Gustatory audition; a hitherto undescribed variety of synaesthesia. Am J Psychol. 1907;18:341-52.

84. Smith BC. Is a sip worth a thousand words? World Fine Wine. 2008;21:114-9.

85. Yeshurun $Y$, Sobel N. An odor is not worth a thousand words: from multidimensional odors to unidimensional odor objects. Annu Rev Psychol. 2010;61:219-41.

86. Prescott J. Taste matters: why we like the foods we do. London: Reaktion Books; 2012.

87. Charters S, Pettigrew S. Is wine consumption an aesthetic experience? J Wine Res. 2005;16:121-36

88. Rudmin F, Cappelli M. Tone-taste synesthesia: a replication. Percept Mot Skills. 1983;56:118.

89. Bartoshuk LM. Separate worlds of taste. Psychol Today. 1980;14:48-9,51,546,63 .

90. Flint PB. Lawrence Welk the TV maestro of champagne music dies at 89 New York Times. 1992;19:B8.
91. Buser HR, Zanier C, Tanner H. Identification of 2,4,6-trichloroanisole as a potent compound causing cork taint in wine. J Agr Food Chem. 1982;30:359-62.

92. Mazzoleni V, Maggi L. Effect of wine style on the perception of 2,4,6trichloroanisole, a compound related to cork taint in wine. Food Res Int 2007:40:694-9.

93. Prescott J, Norris L, Kunst M, Kim S. Estimating a "consumer rejection threshold" for cork taint in white wine. Food Qual Pref. 2005;16:345-9.

94. Goode J. Wine science. London: Mitchell Beazley; 2005.

\section{Submit your next manuscript to BioMed Central and we will help you at every step:}

- We accept pre-submission inquiries

- Our selector tool helps you to find the most relevant journal

- We provide round the clock customer support

- Convenient online submission

- Thorough peer review

- Inclusion in PubMed and all major indexing services

- Maximum visibility for your research

Submit your manuscript at www.biomedcentral.com/submit 